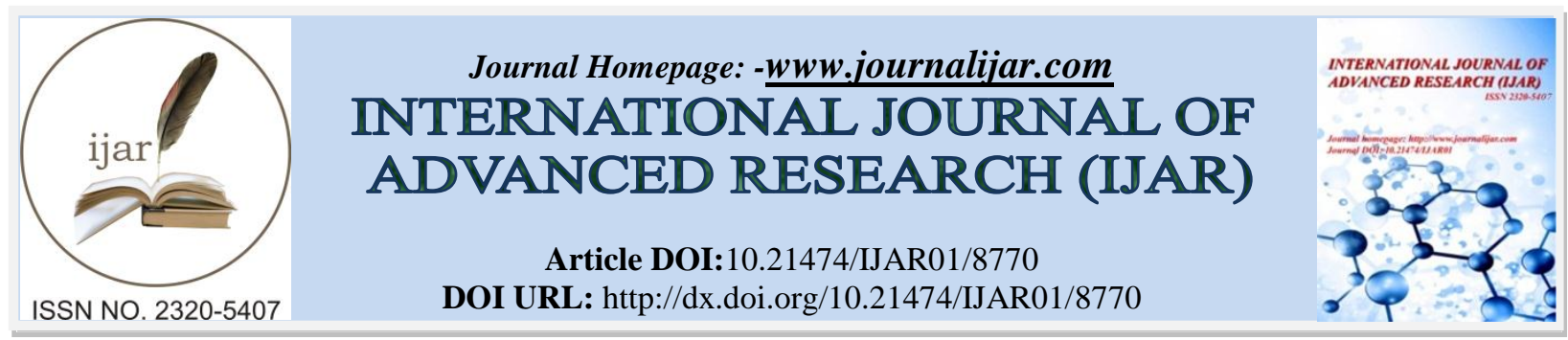

RESEARCH ARTICLE

\title{
SERUM C-PEPTIDE CONCENTRATIONS IN WOMEN WITH POLYCYSTIC OVARIAN SYNDROME (PCOS).
}

Dr.B.Divya Dharshini, Pasupuleti Pallavi, Dr.D.S.S. Girijavani, Dr.B.K.Durgaprasad and Manasa.

1. Assistant Professor, Department Of Biochemistry, Gitam Institute Of Medical Sciences And Research (Gimsr), Visakhaptnam.

2. Third Year Mbbs, Gimsr, Visakhaptnam.

3. Professor And Hod Biochemistry, Gimsr, Visakhaptnam.

4. professor, department of radiology, Gimsr, Visakhaptnam.

5. Gimsr, Visakhaptnam.

\section{Manuscript Info}

\section{Manuscript History}

Received: 20 January 2019

Final Accepted: 22 February 2019

Published: March 2019

\section{Key words:-}

polycystic ovarian syndrome, C-peptide, insulin resistance, Rotterdam criteria.

\section{Abstract}

Background:Polycystic ovarian syndrome (PCOS) is a heterogenous endocrine disorder affecting majority of women in reproductive age. The major endocrine disruption being excessive androgen production and abnormal insulin activity. Excess body weight in women with PCOS accelerates progression towards diabetes by exacerbating both insulin resistance and inappropriate insulin response. As Insulin levels are related to C-peptide levels and as insulin resistance is key finding in PCOS women, increased serum insulin and serum CPeptide concentrations are considered to be a major finding in PCOS.

Methods: Its a case control study was carried out in Gitam institute of medical sciences and research hospital during june 2018 to august 2018 which includes 60 females aged between 17-29 years. Out of 60 female participants, 30 females were cases with PCOS and the remaining 30 were age matched apparently healthy females. Diagnosis of PCOS is based on 2 of 3 findings - oligo/anovulation, hyperandrogenism, polycystic ovaries in ultrasound (Rotterdam criteria).

Results:Serum C-peptide concentrations measured in cases and controls were analysed by SPSS statistical software 23.0. The means of C-peptide between case and control group were compared by unpaired student t-test. $P$ value less than 0.05 were considered statistically significant. The mean \pm SD of C-peptide in case group (women with PCOS) was 3.24 \pm 0.51 $\mathrm{ng} / \mathrm{ml}$ which was significantly higher $(\mathrm{P}<0.05)$ than mean of control group (women without PCOS).

Conclusion:This study showed significantly higher serum C-peptide concentrations in women with PCOS confirming the presence of insulin resistance in PCOS women.

Copy Right, IJAR, 2019,. All rights reserved.

Corresponding Author:-Dr.B.Divya Dharshini.

Address:-Assistant Professor, Department Of Biochemistry, Gitam Institute Of Medical Sciences

And Research (Gimsr), Visakhaptnam. 


\section{Introduction:-}

Polycystic ovarian syndrome (pcos) is the most common and complex endocrine disorder affecting women of reproductive age. It is characterised by heterogenous presentation of hyperandrogenism, ovulatory dysfunction, polycystic ovaries and with considerable prevalence of insulin resistance. Pcos is considered as a multifactorial disorder with genetic, endocrine and environmental abnormalities ${ }^{(1)}$.

PCOS patients present with varied signs and symptoms, making it difficult for its diagnosis and grading. Diagnosis of PCOS is currently based on Rotterdam criteria also known as ESRHE/ASRM criteria. The prevalence of PCOS varies depending on criteria used for diagnosis and it is found to be as high as $15-20 \%$ when European society for human reproduction and embryology (ESHRE) / Rotterdam / American society for reproductive medicine (ASRM) criteria are used ${ }^{(2)}$. In 1980s, LH/FSH ratio $>2$ was considered as gold standard for diagnosis of PCOS. Later, numerous studies were done and found that elevated gonadotropin levels are not found in all the patients and there is separate type of PCOS with normal gonadotropin levels and hence LH and FSH are removed from criteria for its diagnosis ${ }^{(3)}$.

PCOS is considered to be risk factor for developing Diabetes mellitus. Insulin resistance is prevalent in PCOS women, and it is found to play critical role in the development of metabolic and reproductive complications of PCOS. The signs and symptoms of PCOS begin before the signs and symptoms of insulin resistance. As PCOS carries an inherent risk of insulin resistance metabolic screening for PCOS in women with PCOS should be done regardless of BMI or degree of obesity ${ }^{(4)}$. Few Studies have proved that Insulin resistance is manifested in obese, overweight and also in lean PCOS women. But there are also studies which suggests obesity acts as environmental factor and trigger for insulin resistance in PCOS women ${ }^{(5,6)}$.

Insulin resistance in PCOS occurs mostly due to post binding defect in insulin receptor signalling. Insulin resistance and hyperinsulinemia contributes to hyperandrogenism by stimulating androgen production by ovaries ${ }^{(7)}$. PCOS patients have high risk for metabolic and cardiovascular diseases especially after menopause. During fertile period it causes anovulatory infertility, gestational complications such as miscarriages, gestational diabetes, preeclampsia ${ }^{(8)}$.

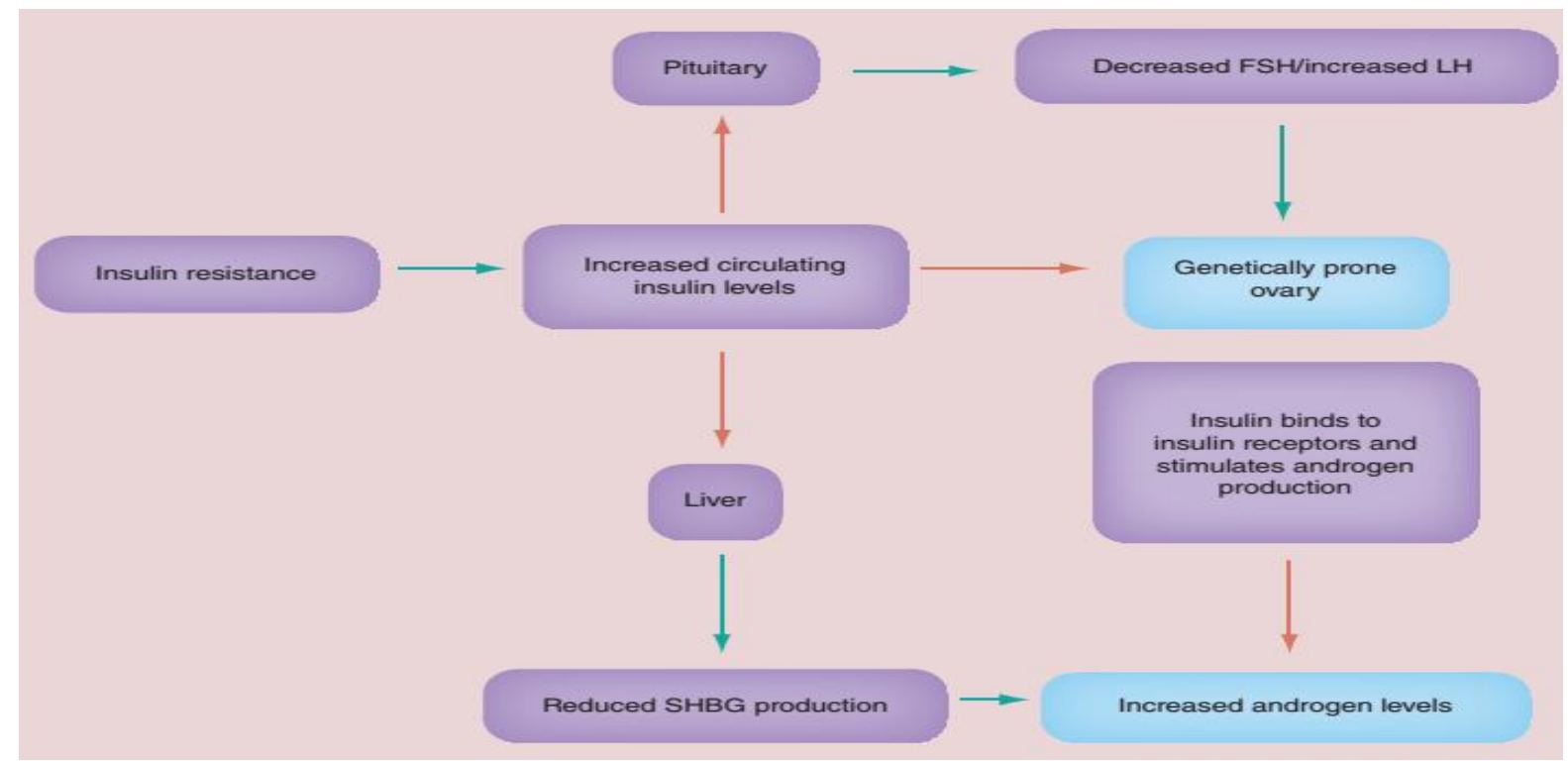

Figure 1:-Showing Insulin resistance and consequences in PCOS

The connecting peptide also known commonly as C-peptide, is a short 31-amino-acid polypeptide that connects A-chain to B-chain in the proinsulin molecule. In the insulin synthesis pathway, preproinsulin which has an A-chain, a C-peptide, a B-chain, and a signal sequence is translocated into the endoplasmic reticulum of beta cells of the pancreas. The signal sequence is cleaved from the $\mathrm{N}$-terminus of the peptide by a peptidase forming proinsulin. This proinsulin reaches Golgi apparatus in the form of vesicles and there C-peptide is removed. Now the A-chain and B-chain are bound together by disulfide bonds that constitute the Insulin molecule ${ }^{(9)}$. 
Measuring C-peptide can help to determine how much of insulin a person is producing as C-peptide is secreted in equimolar amounts to insulin. Since C-peptide and insulin are produced at the same rate, C-peptide is a useful marker of insulin production ${ }^{(10)}$. A high level of serum C-peptide indicates high level of endogenous insulin which can be due to response to high blood glucose or insulin resistance. A low level of C-peptide is associated with a low level of insulin production ${ }^{(1)}$.

C-peptide levels are measured in women with PCOS to determine the presence and the extent of insulin resistance. With this background, we want to study the levels of serum C-peptide in women with Polycystic ovarian syndrome (PCOS).

Aims And Objectives:-

The prime objective of our study is to determine serum C-peptide concentrations in women with Polycystic ovarian syndrome (PCOS).

\section{Material And Methods:-}

It's a Case-control study which includes 60 subjects with cases $(n=30)$ and controls $(n=30)$

Cases include 30 female patients between 17-29 years with PCOS who attended GITAM Institute of Medical Sciences and Research Hospital (GIMSR).

Controls include 30 Age matched apparently healthy female participants.

\section{Cases:}

\section{Inclusion criteria:}

1. Female patients of age group ranging from 17-29 years.

2. Females who are newly diagnosed to have PCOS based on Rotterdam criteria.

3. Females with PCOS who are not on treatment.

\section{Exclusion criteria:}

1. Patients with diabetes mellitus

2. Pregnant and lactating women

3. Patients on any medications that act on hypothalamic-pituitary-gonadal axis such as contraceptives, hormonal therapy (estrogens or progestins), endocrine therapy for breast cancer, GnRH analogues etc., and drugs that alter prolactin levels like anti-psychiatric drugs.

4. Patients with hyperandrogenemia or oligomenorrhoea due to other endocrine causes like androgen producing tumours, adrenal hyperplasia, prolactinomas, premature ovarian failure, primary hypothalamic amenorrhoea.

5. Conditions that produce symptoms similar to PCOS like Cushing's syndrome, hypothyroidism etc.

\section{Study design :}

1. Institutional Ethics Committee (IEC) clearance approval was obtained before the start of the study. Each participant was explained about the details of the study and informed consent obtained. The study was conducted for a period of 2 months between july to august 2018 .

2. Participants for the study were selected by taking detailed history and by Ultrasound abdomen findings. Subjects categorised into two groups as cases and controls based on Rotterdam criteria of diagnosis of PCOS.

3. $5 \mathrm{ml}$ of blood sample was withdrawn from participants after overnight fasting of 10-12 hours. Blood samples collected from both cases and controls were centrifuged at $3000 \mathrm{rpm}$ for $15 \mathrm{~min}$. Serum was separated and stored at $-20^{0} \mathrm{C}$ until analysis.

4. Sample test tubes were appropriately labeled and all specimens were considered as potentially infectious. Hemolysed samples or samples with insufficient volumes were rejected.

5. Serum C-peptide concentrations were estimated in the serum samples by Electrochemiluminescent immunoassay (ECLIA) in ROCHE cobas e411 instrument.

6. The normal reference range for C-peptide is $0.8-3.1 \mathrm{ng} / \mathrm{mL}$. 


\section{Observations And Results:-}

1. Data were analysed by SPSS statistical software 23.0 Windows software (Statistical Package for Social Sciences, SPSS Inc).

2. The statistics of variables will be present in titre of mean \pm SD.

3. C-peptide level measured in the two groups (cases and controls) included in the study were analysed statistically.

4. The means of C-peptide between groups were compared by unpaired student t-test.

5. P value less than 0.05 were considered to be statistically significant.

\section{Results:}

Our study group comprises of 60 women between age group 17-29 years. Of these 30 women were cases $(n=30)$ who were diagnosed as having PCOS and remaining 30 women were controls $(n=30)$ who were age matched and apparently healthy women.

The statistics of all variables in the control group are illustrated in the table 1

Table 1:-Variables in control group

\begin{tabular}{|c|c|c|c|c|c|c|}
\hline \multicolumn{2}{|c|}{ Parameter } & $\mathbf{N}$ & Minimum & Maximum & Mean & SD \\
\hline \multirow[t]{5}{*}{ Control } & Age & 30 & 19 & 21 & 19.67 & 0.55 \\
\hline & Height $(\mathrm{cm})$ & 30 & 149 & 179 & 161.03 & 6.09 \\
\hline & Weight (kg) & 30 & 42 & 78 & 57.20 & 10.21 \\
\hline & BMI & 30 & 17.00 & 31.20 & 22.19 & 3.79 \\
\hline & $\begin{array}{l}\text { CPEPTIDE } \\
(\mathrm{ng} / \mathrm{ml})\end{array}$ & 30 & 0.19 & 1.26 & 0.69 & 0.23 \\
\hline
\end{tabular}

The observations of the variables in women without PCOS group (controls) as shown in table 1 were as follows: the mean \pm SD of age in years for this group is $19.67 \pm 0.55$. The mean \pm SD of height in cms for this group is $161.03 \pm$ 6.09. The mean \pm SD of weight in kgs for this group is $57.20 \pm 10.21$. The mean \pm SD of BMI for this group is 22.19 \pm 3.79 . The mean $\pm \mathrm{SD}$ of $\mathrm{C}$-peptide in $\mathrm{ng} / \mathrm{ml}$ for this group is $0.69 \pm 0.23$.

The statistics of all variables in the Case group are illustrated in the table 2

Table 2:-Variables in case group

\begin{tabular}{|l|l|l|l|l|l|l|}
\hline \multicolumn{2}{|l|}{ Parameter } & N & Minimum & Maximum & Mean & SD \\
\hline Cases & Age (yrs) & 30 & 17 & 22 & 19.33 & 1.06 \\
\cline { 2 - 7 } & Height (cm) & 30 & 146 & 177 & 163.87 & 7.46 \\
\cline { 2 - 7 } & Weight (kg) & 30 & 32 & 90 & 62.23 & 13.59 \\
\cline { 2 - 7 } & BMI & 30 & 15.00 & 31.90 & 23.05 & 4.13 \\
\cline { 2 - 7 } & CPEPTIDE (ng/ml) & 30 & 2.66 & 4.87 & 3.24 & 0.51 \\
\hline
\end{tabular}

The observations of the variables in women with PCOS categorised into the case group were as follows : The mean \pm SD of age in years for this group is $19.33 \pm 1.06$. The mean \pm SD of height in cms for this group is $163.87 \pm 7.46$. The mean $\pm \mathrm{SD}$ of weight in kgs for this group is $62.23 \pm 13.59$. The mean $\pm \mathrm{SD}$ of BMI for this group is $23.05 \pm 4.13$. The mean of C-peptide in $\mathrm{ng} / \mathrm{ml}$ for this group is $3.24 \pm 0.51$ as shown in table 2 . 


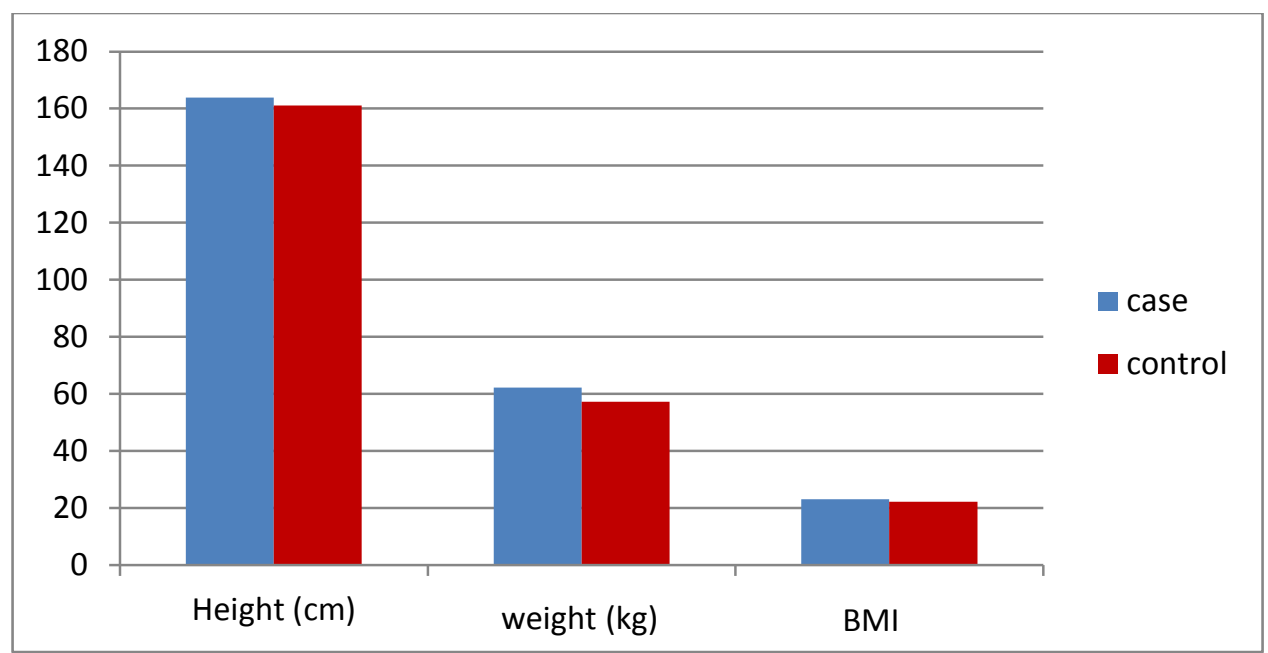

Figure 2:-Comparison of means of height, weight, BMI among two groups

The means of height, weight and BMI for cases and control were compared as shown in figure 2. This shows that mean \pm SD of height in cms was $163.87 \pm 7.46$ in cases and $161.03 \pm 6.09$ in controls. The mean \pm SD of weight in $\mathrm{kgs}$ was $62.23 \pm 13.59$ in case group and $57.20 \pm 10.21$ in control group. The mean \pm SD of BMI in case group is $23.05 \pm 4.13$ and $22.19 \pm 3.79$ in control group. The mean of height, weight and BMI are approximately same for both case and control group.

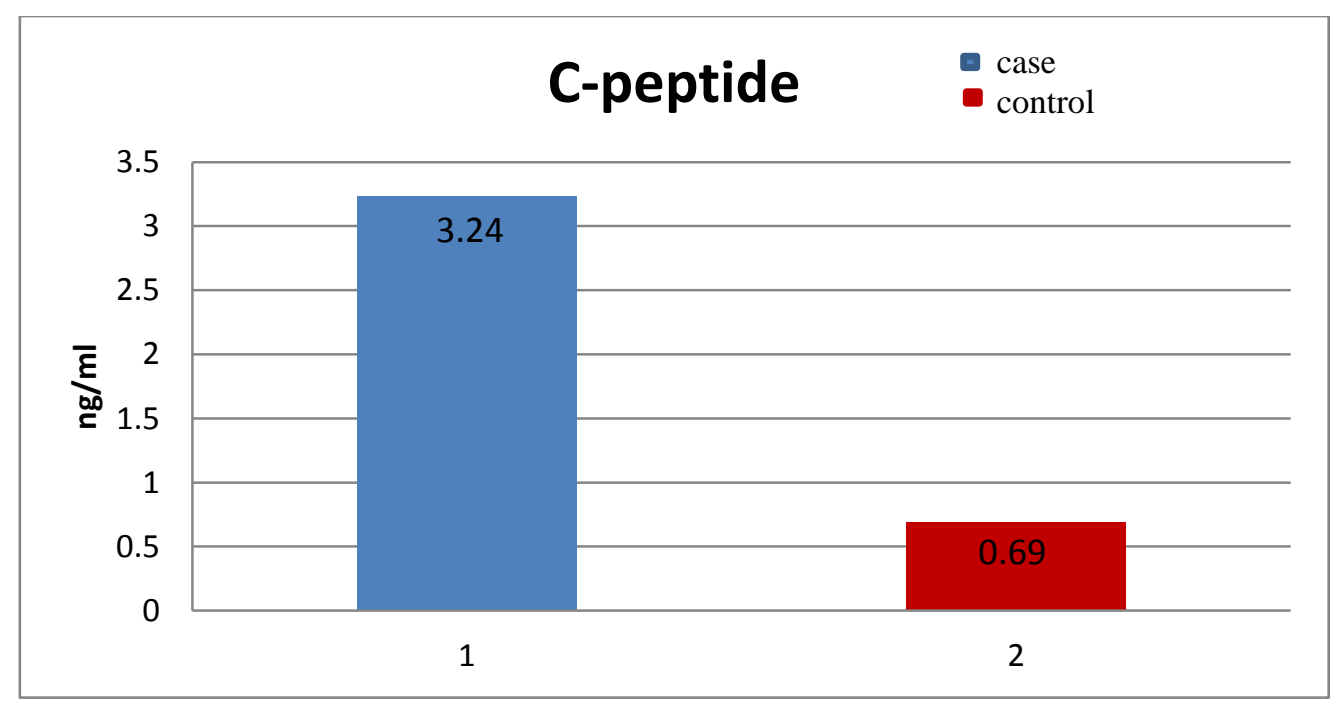

Figure 3:-Comparison of means of C-peptide among cases and controls

The means of C-peptide for two groups of cases and controls were compared as shown in figure 3 . This shows that the mean \pm SD of C-peptide in $\mathrm{ng} / \mathrm{ml}$ was $3.24 \pm 0.51$ in case group and $0.69 \pm 0.23$ in control group. The mean of $\mathrm{C}$-peptide in cases was much higher than in controls. 


\begin{tabular}{|l|l|l|l|l|l|l|}
\hline \multirow{2}{*}{ Parameters } & Case & Control & t - value & \multirow{2}{*}{ P- value } \\
\cline { 2 - 6 } & Mean & SD & Mean & SD & & \\
\hline Height $(\mathrm{cm})$ & 163.87 & 7.46 & 161.03 & 6.09 & 1.61 & 0.11 \\
\hline Weight $(\mathrm{kg})$ & 62.23 & 13.59 & 57.20 & 10.21 & 1.62 & 0.11 \\
\hline BMI & 23.05 & 4.13 & 22.19 & 3.79 & 0.83 & 0.41 \\
\hline CPEPTIDE $(\mathrm{ng} / \mathrm{ml})$ & 3.24 & 0.51 & 0.69 & 0.23 & 24.29 & $<0.01$ \\
\hline
\end{tabular}

Table 3:-Comparison between case and controls by unpaired student t-test

We compared the means of all the variables of the two groups by unpaired student t-test.

The serum C-peptide concentration was statistically significantly higher in cases when compared to controls given by $\mathrm{P}$ value $(\mathrm{P}<0.01)$ as shown in table 3.

\section{Discussion:-}

The present study includes detailed clinical history taking of the women and they are radiologically diagnosed based on Ultrasound abdomen for presence or absence of Polycystic ovaries. Based on clinical history and radiological findings (according to Rotterdam criteria), the study group was categorized into women with PCOS (cases) and women without PCOS (controls). The study group (cases and controls) were analysed for C-peptide (connecting peptide) in serum. Normal reference range for C-peptide is $0.8-3.1 \mathrm{ng} / \mathrm{ml}$ for the method and instrument selected for analysis. The value of $\mathrm{C}$-peptide more than $3.1 \mathrm{ng} / \mathrm{ml}$ was considered as having insulin resistance and samples with value less than $3.1 \mathrm{ng} / \mathrm{ml}$ was considered as not having insulin resistance.

Our study group of 60 participants out of which 30 were cases and remaining 30 were controls.

\section{C-peptide in cases and controls}

The mean \pm SD of C-peptide in $\mathrm{ng} / \mathrm{ml}$ in women with PCOS i.e., cases is $3.24 \pm 0.51$ as shown in table 2 and the mean \pm SD of C-peptide in $\mathrm{ng} / \mathrm{ml}$ in women without PCOS is $0.69 \pm 0.23$ as shown in table 1 . This shows that the mean for C-peptide was significantly high in women with Polycystic ovarian syndrome (PCOS) when compared to women without PCOS.

A high level of C-peptide generally indicates a high level of endogenous insulin production. This increased concentration of C-peptide in women with PCOS when compared to women without PCOS indicates that PCOS women are highly subjected to develop insulin resistance when compared to normal women without PCOS. This correlated with studies done by M.Maliqueo et $\mathrm{al}^{(12)}$, Melania Manco, et $\mathrm{al}^{(15)}$, J. Stassek et al ${ }^{(13)}$ and Mahabeer S et $\mathrm{al}^{(14)}$.

Incidence of insulin resistance in PCOS patients is high. Insulin resistance and hyperinsulinemia causes increase in steroidogenesis(hyperandrogenesim) and LH release in PCOS women ${ }^{(16)}$. The mechanism of association of insulin resistance in PCOS is believed to be due to excessive serine phosphorylation of the insulin receptor, this in turn decreases protein tyrosine kinase activity which is considered one of the important mechanism for post binding defect in insulin action in PCOS ${ }^{(17)}$. Serine/ threonine kinase that phosphorylates serine residues of beta subunit of insulin receptor also increases serine phosphorylation of $\mathrm{P} 450 \mathrm{c} 17 \alpha$ which is involved in androgen biosynthesis hence leading to increased production of androgens ${ }^{(18,19)}$.

In 1921, Emile Achard and Joseph Thiers showed that there is link between insulin resistance and PCOS and later in a study done in 1976 found that young women who are hyperinsulinemic have genetic defect in the insulin receptor and thus it led to the concept that insulin may play a critical role in PCOS ${ }^{(20,21)}$. Diamanti-Kandarakis E et al., has studied the mechanism which leads to insulin resistance which is mainly due to defects in insulin binding to its receptor and changes in signal transduction ${ }^{(22)}$.

Studies have shown that obesity is common finding in PCOS and there is higher prevalence of insulin resistance in overweight and obese women with PCOS. There are also studies which showed prevalence of insulin resistance in women independent of obesity. According to this study all the participants (both case and control group) fall in the healthy weight range according to their BMI, showing that the case and control group were even BMI matched. And still insulin resistance was seen in case group of women with PCOS. 


\section{Conclusion:-}

1. Our study has established association of elevated levels of serum C-peptide in Polycystic ovarian syndrome (PCOS) women. This indicates presence of insulin resistance in women with PCOS.

2. C-peptide measurements can be used as marker for insulin resistance and early life style modifications can reduce the risk of Type 2 diabetes mellitus, cardiovascular diseases and other morbidities associated with PCOS.

3. As affected women have marked insulin resistance independent of obesity, more interventional studies are needed to draw conclusions on the association of insulin resistance and obesity in PCOS.

\section{References:-}

1. V. De Leo, M. C. Musacchio, V. Cappelli et al., Genetic, hormonal and metabolic aspects of PCOS: an update Reproductive Biology and Endocrinology $\quad$ (2016) DOI 10.1186/s12958-016-0173.

2. Susan M Sirmans, Kristen A Pate et al., Epidemiology, diagnosis, and management of polycystic ovary syndrome Clinical Epidemiology 2014:6 1-13.

3. Berger MJ, Taymor ML, Patton WC et al., Gonadotropin levels and secretory patterns in patients with typical and atypical polycystic ovarian desease. Fertil Steril, 1975; 26: 619-27.

4. Stéphanie B Mayer, William S Evans \& John E Nestler., Polycystic ovary syndrome and insulin: our understanding in the past, present and future., Womens Health (2015) 11(2), 137-149.

5. Evanthia Diamanti-Kandarakis and Andrea Dunaif ., Insulin Resistance and the Polycystic Ovary Syndrome Revisited: An Update on Mechanisms and Implications 2012 Oct 12., 10.1210/er.2011-1034.

6. Maciejewska-Jeske M, Szczesna A, Męczekalski B et al., Serum C-peptide concentration in overweight and obese women with polycystic ovary syndrome Pol Merkur Lekarski. 2010 Aug; 29(170):93-9.

7. Franks S, Mc Carthy M, Hardy K et al., Development of polycystic ovary syndrome: involvement of genetic and environmental factors. Int J Androl. 2006;29:278-85.

8. De Leo V, La Marca A. Petraglia F et al., Insulin-lowering agents in the management of polycystic ovary syndrome. Endocr Rev. 2003;24:633-67.

9. Steiner D.F, Cunningham D,Spigelman L,et al., Insulin Biosynthesis: Evidence for a Precursor. Science. 157 (3789): 697-700.

10. Clark PM et al., Assays for insulin, proinsulin and C-peptide. Ann Clin Biochem 1999; 36: 541-564.

11. Polonsky KS, Licinio-Paixao J., et al. Use of biosynthetic human C-peptide in the measurement of insulin secretion rates in normal volunteers and type I diabetic patients. J Clin Invest 1986; 77: 98-105.

12. M.Maliqueo1, I.Atwater2., Proinsulin serum concentrations in women with polycystic ovary syndrome: a marker of b-cell dysfunction, Human Reproduction Vol.18, No.12 pp. 2683 $\pm 2688,2003$

13. J. Stassek, J. Erdmann et al., C-Peptide, Baseline and Postprandial Insulin Resistance after a Carbohydrate-Rich Test Meal - Evidence for an Increased Insulin Clearance in PCOS Patients, Geburtshilfe Frauenheilkd. 2017 Jan; 77(1): 5965.

14. Mahabeer S , Jialal et al., Insulin and C-peptide secretion in non-obese patients with polycystic ovarian disease. Horm Metab Res. 1989 Sep;21(9):502-6.

15. Melania Manco et al., Insulin Dynamics in Young Women with Polycystic Ovary Syndrome and Normal Glucose Tolerance across Categories of Body Mass Index., PLoS One. 2014; 9(4): e92995.

16. Lobo RA, Carmina E. The importance of diagnosing the polycystic ovary syndrome. Ann Intern Med 2000;132: 98993.

17. Dunaif A, Xia J, Book CB, Schenker E et al., Excessive insulin receptor serine phosphorylation in cultured fibroblasts and in skeletal muscle. A potential mechanism for insulin resistance in the polycystic ovary syndrome. J Clin Invest 1995;96:801-10.

18. Dunaif A et al., Insulin resistance and the polycystic ovary syndrome: mechanism and implications for pathogenesis. Endocrine Rev 1997;18:774-800.

19. Zhang LH, Rodriguez H, Ohno S et al., Serine phosphorylation of human P450c17 increases 17,20-lyase activity: implications for adrenarche and the polycystic ovary syndrome. Proc Natl Acad Sci USA 1995;92: 10619-23.

20. Kahn CR, Flier JS, Bar RS et al. The syndromes of insulin resistance and acanthosis nigricans. Insulin-receptor disorders in man. N. Engl. J. Med. 294(14), 739-745 (1976).

21. Taylor SI, Dons RF, Hernandez E et al., Insulin resistance associated with androgen excess in women with autoantibodies to the insulin receptor. Ann. Intern. Med. 97(6), 851-855 (1982).

22. Diamanti-Kandarakis E, Argyrakopolou G, Economou F, et al. Defects in insulin signaling pathways in ovarian steroidogenesis and other tissues in polycystic ovary syndrome. J Steroid Biochem an Molecular Bio. 2008;109:242-6. 